\title{
Influence of Shale Gas Components on Jet Diffusion Flame
}

\author{
Liu Shuai ${ }^{a, *} \quad$ Wang Zhong ${ }^{b} \quad$ Zhao Yang $^{c} \quad$ Li Ruina Qu Lei \\ Jiangsu University, School of Automobile and Traffic Engineering, Zhenjiang 212013,China \\ alstcls@163.com ㄴ22629217@qq.com c171553404@qq.com
}

Key words: Shale gas; component; jet diffusion flame; computational fluid mechanics; methane Abstract: Effect of different shale gas components on jet diffusion flame were studied using mathematical method in this paper. Changes of $\mathrm{OH}$ free radical in jet diffusion flame of two different shale gas components were researched, and the impacts of shale gas composition changes on mass fraction of methane, combustion velocity and temperature fields were also discussed compared with vehicle compression natural gas jet diffusion flames. The results show that, in process of shale gas diffusion combustion, $\mathrm{OH}$ free radical mainly in outer flame, higher concentration of $\mathrm{OH}$ free radicals produced by the combustion of shale gas with higher mass fraction of methane at the top of the flame; in the region the flame height is in the range of $0 \sim 3 \mathrm{~cm}$, mass fraction of methane is higher, methane consumption is fastest, and combustion is most intense; compared with shale gas with methane mass fraction of $62.9 \%$ and vehicle compression natural gas with methane mass fraction of $87.36 \%$, shale gas with methane mass fraction of $93.5 \%$ has the highest Combustion temperature and the fastest combustion speed.

\section{Introduction}

Shale gas refers to exist in organic-rich shales and dissection, and mainly in the form of adsorption or free state, is an unconventional natural gas, composed mainly of methane. China is rich in shale gas resources, according to the Energy Information Administration's forecast, the reserves of global shale gas are $456 \times 10^{12} \sim 716 \times 10^{12} \mathrm{~m}^{3}$, shale gas resources in China reaches 100 $\times 10^{12} \sim 144.4 \times 10^{12} \mathrm{~m}^{3}$, accounts for about 20 percent of the world's total reserves ${ }^{[1]}$. Due to the difference accumulation mechanism of shale gas, shale gas composition changes largely in the different regions, change interval of methane is $46.5 \% \sim 99.8 \%{ }^{[2-4]}$.

Around the jet diffusion flames of natural gas and other gaseous fuel, domestic and foreign scholars have conducted researches. Zhang Yongming and Fang Jun ${ }^{[5]}$ of University of Science and Technology of China, who used jet burner to study jet diffusion flame of Methane in the low pressure test chamber, when the mass flow of fuel increases, flame temperature and flame radiation heat increased. Zhao Zhenxing ${ }^{[6]}$ of Xi'an Jiaotong University, who used different structure of burner to study ignition characteristics and combustion stability of gas, when inside diameter less than $8 \mathrm{~mm}$ of burner, combustion stability decreased, when the concentration of hydrogen increased, combustion stability of gas increased. Research Status shows that, when the components of gas changed, the flame structure of jet diffusion combustion was differences, the component of shale gas in different parts was large differences. Necessary around the impact the component of shale gas changes research.

According to China's two regions of shale gas abundant rich reserves, used Non-premixed combustion model of FLUENT6.3, studied the impact of jet diffusion flame when the component of shale gas changed. Analysis of the changes of combustion temperature, velocity and mass fraction of reactants and products, explored the impact of the burner temperature of the central axis, speed 
and distribution of the material. When flame height was different, studied the law of temperature and velocity and distribution of material.

\section{Gas Components and Programs}

China's shale gas reserves are mainly concentrated in two regions, Changning County of Sichuan Province and its surrounding areas, and Zhaotong of Yunnan Province and its surrounding areas $^{[7]}$. Because there are some differences between the geological structure and the mechanism of accumulation, there is a big difference between the two areas of component of shale gas. The volume fraction of the shale gas of $\mathrm{C}_{1} \sim \mathrm{C}_{4}$ hydrocarbons in Changning is $96.7 \% 、 1.2 \% 、 0.1 \%$ 、 $0 \%$, the volume fraction of the shale gas of $\mathrm{C}_{1} \sim \mathrm{C}_{4}$ hydrocarbons in Zhaotong is $78.9 \% 、 12.6 \%$ 、 $4.9 \% 、 0.76 \%$. Based on the conversion equation between mass fraction and volume fraction, we can get the mass fraction of each alkane gases of shale gas, conversion equation is as follows,

$$
g_{i}=\frac{r_{i} m_{i}}{\sum r_{i} m_{i}} \times 100
$$

Shale gas can be considered an unconventional natural gas, based on the relevant national standards of $\mathrm{CNG}$, determine the representative gas component of CNG. In order to study the difference of diffusion flame jet between shale gas and conventional gas diffusion, studied the conventional gas diffusion combustion jet.

Table1 shows the different shale gas and CNG each alkanes gas mass fraction. As shown in Table1, program1 representative of Changning district shale gas, program2 representative of Zhaotong district shale gas, program 3 representative of CNG.

Tab.1 The Mass Fraction of Each Component in Different Options

\begin{tabular}{|c|c|c|c|c|c|}
\hline Program & Methane & Ethane & Propane & Butane & Alkanes total amount of gas \\
\hline 1 & 0.935 & 0.022 & 0.003 & 0 & 0.96 \\
\hline 2 & 0.629 & 0.188 & 0.107 & 0.022 & 0.946 \\
\hline 3 & 0.874 & 0.043 & 0.017 & 0.015 & 0.949 \\
\hline
\end{tabular}

\section{Mathematical Model and Mesh}

\section{Mathematical Model}

Flow model uses the standard k- $\varepsilon$ model, it applies to simulate turbulent flow in the pipe and channel. Standard k- $\varepsilon$ model is a semi-empirical formula, it mainly based on the turbulent kinetic energy and diffusivity. $\mathrm{k}$ equation is the exact equation, $\varepsilon$ equation derived from the empirical formula. Equation is as follows,

Turbulent kinetic energy equation,

$$
\frac{\partial(\rho k)}{\partial t}+\frac{\partial}{\partial x_{j}}\left(\rho \overline{u_{j}} k\right)=-\frac{\partial}{\partial x_{j}}\left[\left(\mu+\frac{\mu_{t}}{\sigma_{k}}\right) \frac{\partial k}{\partial x_{j}}\right]+\mu_{t} \frac{\partial \overline{u_{j}}}{\partial x_{i}}\left(\frac{\partial \overline{u_{j}}}{\partial x_{i}}+\frac{\partial \overline{u_{i}}}{\partial x_{j}}\right)-\rho \varepsilon
$$

Turbulent kinetic energy dissipation rate equation,

$$
\frac{\partial(\rho \varepsilon)}{\partial t}+\frac{\partial}{\partial x_{j}}\left(\rho \overline{u_{j}} \varepsilon\right)=-\frac{\partial}{\partial x_{j}}\left[\left(\mu+\frac{\mu_{t}}{\sigma_{\varepsilon}}\right) \frac{\partial \varepsilon}{\partial x_{j}}\right]+C_{1} \frac{\varepsilon}{K} \mu_{t} \frac{\partial \bar{u}_{j}}{\partial x_{i}}\left(\frac{\partial \bar{u}_{j}}{\partial x_{i}}+\frac{\partial \bar{u}_{i}}{\partial x_{j}}\right)-C_{2} \frac{\varepsilon^{2}}{k}
$$

Turbulent viscosity coefficient $\mu=\rho C_{\mu} k^{2} / \varepsilon$.

This paper uses non-premixed combustion model to simulate, this model is not necessary to solve each component of the transport equation, Solution one or two conserved scalar transport 
equation, according to the forecast of the mixture fraction distribution, derive the concentration of each component. By solving the transient distribution of mixture fraction $f$, we determine the chemical properties of quick response of the fluid, use the probability density function PDF to consider the effect of turbulence.

Radiation model uses the P-1 radiation model, this model has the following two equations,

Radiation equation of qr heat flow,

$$
q_{r}=-\Gamma \nabla G
$$

Transport equation of $\mathrm{G}$ incident radiation,

$$
\nabla(\Gamma \nabla G)-\alpha G+4 \alpha \sigma T^{4}=S_{G}
$$

Among them, $\Gamma$-Parameters introduced

a-Absorption coefficient

$\sigma \mathrm{s}$-Scattering coefficient

$\mathrm{C}$ - - Linear anisotropic phase function coefficient

$\sigma$-Stephen - Boltzmann constant

SG-User-defined radiological

\section{Meshing}

Figure 1 is a diagram burner mesh. As can be seen from Figure 1, the structure of combustion model is cylinder The radius model is $3.6 \mathrm{~cm}$, Height is $7 \mathrm{~cm}$, the gas outlet radius of combustion model is $0.36 \mathrm{~cm}$, the air outlet radius is $0.55 \mathrm{~cm}$, the gas outlet height is $0.36 \mathrm{~cm}$. Using tetrahedral mesh model to divide combustion model, encrypt grid at the gas outlet.

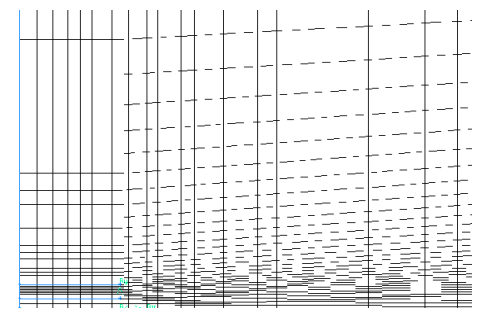

Fig.1 Partial Enlarged View of the Grid

\section{Jet Diffusion Flame Analysis}

\section{The Distribution of OH Radicals and Methane Mass Fraction}

Chain propagation of radical initiator and chain initiation reaction are dynamic of flame propagation, the concentration of free radicals plays an important role in the diffusion combustion, is an important indicator of the stability of the flame. Changes in the concentration of $\mathrm{OH}$ group is most evident in the combustion, combustion rate is closely related to the concentration of the $\mathrm{OH}$ groups of the flame ${ }^{[8]}$. Figure 2 shows the three scenarios jet diffusion combustion, concentration distribution field of $\mathrm{OH}$ radical in the flames. As can be seen from Figure 9, when the gas outlet diameter is $0.72 \mathrm{~cm}$, the exit velocity is $11.4 \mathrm{~cm} / \mathrm{s}, \mathrm{OH}$ radicals concentrated in the outer region of the diffusion flame, external flame zone gas mixes well with air, combustion reaction focus, the reaction rate is faster, the combustion temperature is high, option one in shale gas combustion, the most concentrated area of focus at the top of the flame $\mathrm{OH}$ group, resulting in the combustion temperature is higher and flame speed is faster than other fuels, when option two and option three are burning, concentration distribution of $\mathrm{OH}$ radical looks like option one, $\mathrm{OH}$ group concentration of option three is greater than option two. 

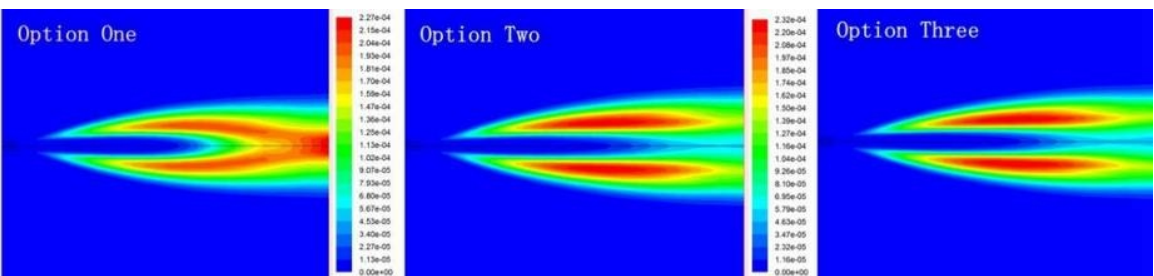

Fig.2 Distribution of OH Radicals in Diffusion Flames

Figure 3 shows when three options are burning, the distribution of the mass fraction of methane gas along the axis. As can be seen from Figure 3, when the gas outlet diameter is $0.72 \mathrm{~cm}$, outlet speed is $11.4 \mathrm{~cm} / \mathrm{s}$, the axial distance is in the range of $0 \sim 0.25 \mathrm{~cm}$, methane mass fraction of three programs remained unchanged, indicate that the area is diverging section of gas, not sufficiently mixed with air, gas is not burning, the axial distance is in the range of $0.25 \sim 1.5 \mathrm{~cm}$, gas is from the diverging section into the larger area, rapid mixing of methane and air, combustion reaction speed is fast, the mass fraction of methane along the central axis is decreases rapidly, comparison of the three scenarios of mass fraction of methane combustion rate of decline can be seen, the mass fraction of methane combustion fastest decline in the option one, is showen that combustion speed is fastest in the option one, the mass fraction of methane is slowest decline in the option two, combustion speed is slow, when the axial distance is $3 \mathrm{~cm}$, the mass fraction of methane of three programs approaches zero, along the central axis of the basic burn methane.

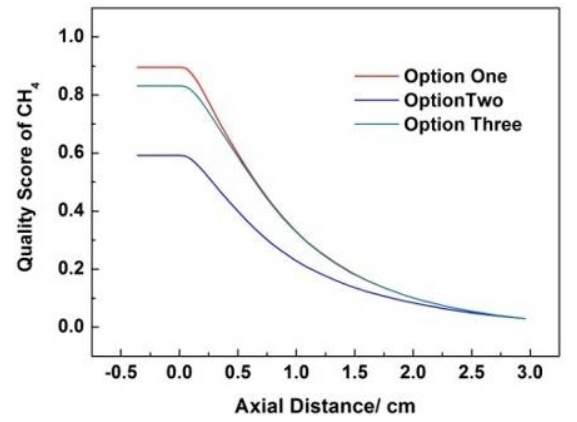

Fig.3 Methane Mass Fraction Distribution Along the Central Axis

\section{Burning Velocity Field}

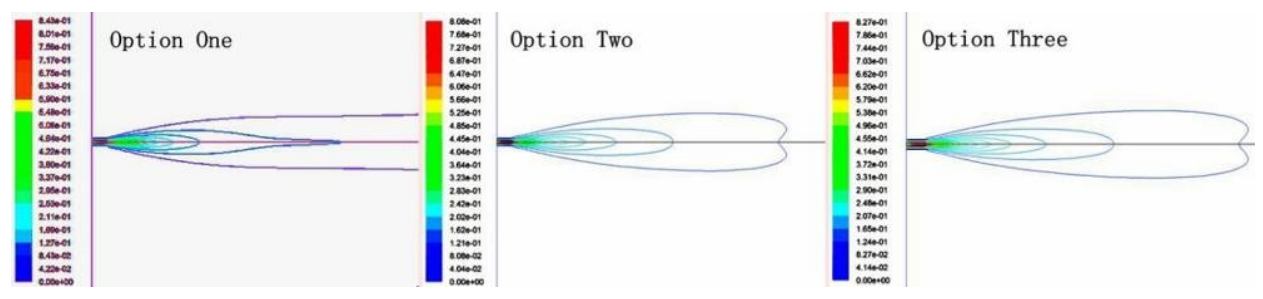

Fig.4 Combustion Velocity Contours Distribution

Figure 4 shows the velocity contours of three scenarios burning jet fuel gas diffusion distribution. As can be seen from Figure 4, when the gas outlet diameter is $0.72 \mathrm{~cm}$, outlet speed is $11.4 \mathrm{~cm} / \mathrm{s}$, combustion velocity of three scenarios of gas vents is distribution, combustion velocity of option two and option three is similar, top convergence that looks like oval spread out, at the top of the outer air stream depression, heart-shaped distribution, combustion rate similar shows gas and air mixing speed close both two programs, combustion speed of gas is be oval distribution in the vicinity of the outlet in option one, outer is no convergence, be open distribution, comparing the contours of combustion velocity of the three options can be seen that, the gas and air mixture speed is slow in the option three, the gas and air mixture speed is fast in the option one. 


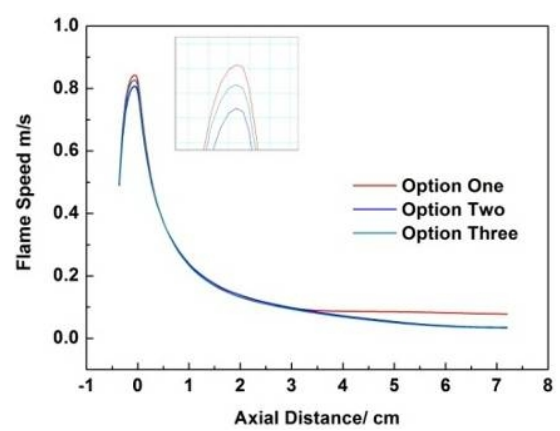

Fig.5 Combustion Velocity Distribution Along the Central Axis

Figure 5 shows that when the jet diffusion of three scenarios is combusting, the distribution of the flame speed along the central axis. As can be seen from Figure 5, when the gas outlet diameter is $0.72 \mathrm{~cm}$, outlet speed is $11.4 \mathrm{~cm} / \mathrm{s}$, the gas combustion speed is $80 \mathrm{~cm} / \mathrm{s}$ or so at the outlet, the speed decreases along the central axis of the outlet, the axial distance in the range of $0 \sim 1 \mathrm{~cm}$, combustion rate dropps $60 \mathrm{~cm} / \mathrm{s}$ or so, the rate of decline is significant, description gas and air mixes full within this range, combustion reaction speed rapid, flame height develops from the outlet location to the $3.5 \mathrm{~cm}$ along the central axis, combustion rate decreases, combustion velocity of the three options are basically same, the gas combustion rate is slightly higher along the central axis of option one, when the flames spread is $3.5 \mathrm{~cm}$, the gas combustion rate basically unchanged of option one, the gas combustion rate decreased slightly of option two and option three.
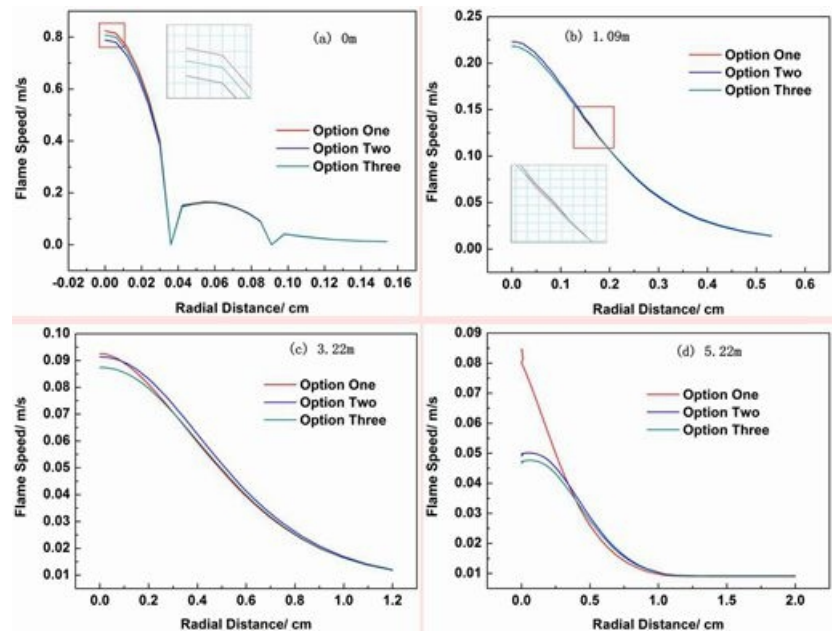

Fig.6 Radial Velocity Distribution at Different Axial Distances

Figure 6 shows that when the gas outlet diameter is $0.72 \mathrm{~cm}$, outlet speed is $11.4 \mathrm{~cm} / \mathrm{s}$, three scenarios jet diffusion combustion, different combustion flame height radial velocity profile, figure (a) is the exit of the radial velocity distribution, figure (b) is $1.09 \mathrm{~cm}$ of axial distance, figure (c) is $5.25 \mathrm{~cm}$ of axial distance, figure (d) is $7.20 \mathrm{~cm}$ of axial distance. As can be seen from figure (a), combustion velocity radius of three option is $0.16 \mathrm{~cm}$, combustion velocity is 3 segments distribution, the combustion have the same speed at the outlet, the combustion speed of option one is higher, reaches $82.4 \mathrm{~cm} / \mathrm{s}$, within a speed radius of $0.04 \mathrm{~cm}$ range, flame propagation speed decreases, the gas and air are rapid mix, within the range of radius of $0.04 \sim 0.085 \mathrm{~cm}$, flame velocity distribution curved, the combustion velocity of three programs is basically the same, as can be seen from figure (b), at an axial distance is $1.09 \mathrm{~cm}$, the radius of flame speed is $0.6 \mathrm{~cm}$, is a monotonically decreasing from radial, combustion velocity of three options are basically the same, as can be seen from figure (c), flame velocity distribution is similar with $1.09 \mathrm{~cm}$, when the axial distance is $3.22 \mathrm{~cm}$, flame speed is monotonically decreasing from radial, speed radius expanded to $1.2 \mathrm{~cm}$, the combustion rate of option two is slightly lower than the other two programs combustion 
rate in the vicinity of the axis, as can be seen from figure (d), axial distance is $5.25 \mathrm{~cm}$, the combustion rate of three options is monotonically decreasing along radial, equilibrium is reached at a radius of $1 \mathrm{~cm}$, in the vicinity of the central axis, option one combustion rate is significantly higher than the burning speed of other programs.

\section{Combustion Temperature Field}
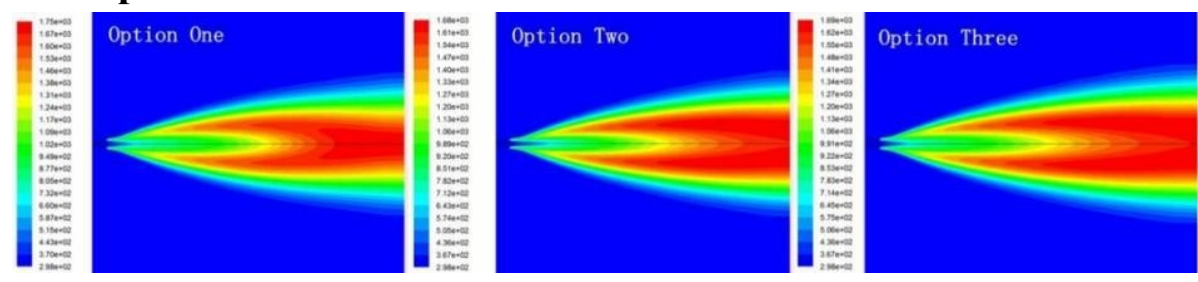

Fig.7 Combustion Temperature Field

Figure 7 shows the different options jet diffusion combustion temperature field. As can be seen from Figure 7, when the gas outlet diameter is $0.72 \mathrm{~cm}$, outlet speed is $11.4 \mathrm{~cm} / \mathrm{s}$, the high temperature zone of combustion is distributed In the flame height is larger than $3 \mathrm{~cm}$, flame radius $0.2 \mathrm{~cm} \sim 0.4 \mathrm{~cm}$, gas and air well mixed in this region, reaches the flammable range, format an external combustion flame, flame height in the range of $3 \mathrm{~cm}$, near the central axis of the jet fire cone, air content is less, gas and air mixture is not sufficient, flame temperature is low, comparison of three combustion temperature field can be seen, the mass fraction of the gas of hydrocarbons is $96 \%$ in option one, mass fraction of $\mathrm{C}$ and $\mathrm{H}$ in the gas is highest, lead to combustion temperature of option one is higher than others, compare with option two and option three combustion temperature field can be seen, the mass fraction of the two solutions close to the gas hydrocarbons, resulting in combustion temperature similar.

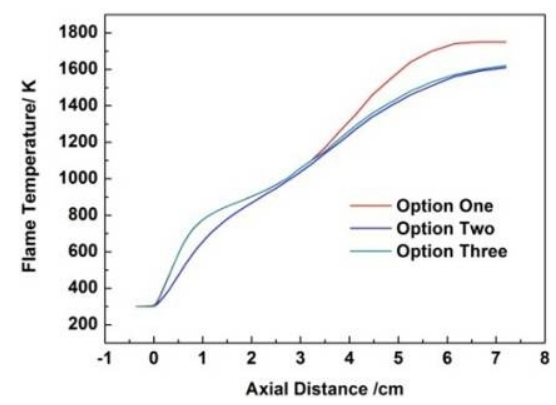

Fig. 8 Combustion Temperature Distribution Along the Central Axis

Figure 8 shows that the temperature of jet diffusion flame of three options located in the central axis. As can be seen from Figure 8, when the gas outlet diameter is $0.72 \mathrm{~cm}$, outlet speed is $11.4 \mathrm{~cm} / \mathrm{s}$, the combustion temperatures of jet diffusion flame increase with height increases flame, in the flame at a height of $1 \mathrm{~cm}$ and $6 \mathrm{~cm}$, combustion temperature appears peak, when shale gas of option one is burning, the combustion temperature of central axis is highest, reaches $1750 \mathrm{~K}$, when the height of the flame is within $4 \mathrm{~cm} \sim 7 \mathrm{~cm}$, combustion temperature is higher than the other two programs $60 \mathrm{~K} \sim 170 \mathrm{~K}$, combined with the combustion temperature distribution can be seen, flame height in the range of $4 \mathrm{~cm} \sim 7 \mathrm{~cm}$, flame radius of option one decreases, gas and air well mixed, combustion is more complete, flame temperature is higher, central axis of the temperature is relatively option two and option three distribution can be seen, when the flame height at about $1 \mathrm{~cm}$, combustion temperature of option two is higher than the combustion temperature of option three, maximum difference is about $140 \mathrm{~K}$, with the increase of flame height, combustion temperature of two options is close. 


\section{Conclusions}

(1) When shale gas and CNG diffusion combustion, the distance along the central axis within the range of $3 \mathrm{~cm}$, methane mass fraction decreases significantly, among them, the mass fraction of methane of option one significant decline, when the shale gas of option two and CNG of option three in vehicles diffusion combustion, the distribution of $\mathrm{OH}$ radicals in the flame, mainly concentrated in the outer flame region of the flame, option one in shale gas combustion flame $\mathrm{OH}$ radicals concentrated at the top.

(2) The diffusion combustion velocity of shale gas of option two and CNG of option three distributions similar, diffusion combustion speed of shale gas of option one is fast, the axial distance is in the range of $1 \mathrm{~cm}$, gas and air mixture fastest, resulting in combustion speed decline significant, with height flame increases, combustion speed monotonically decreasing along the radius.

(3) Methane mass fraction of shale gas of option one is highest, reaches $93.5 \%$, jet diffusion flame combustion temperature is higher than the combustion temperature of the other two programs, along the central axis of the flame temperature is gradually increased, the radius of the flame increases, the combustion temperature of the flame height at different radial unmoral distribution.

\section{Acknowledgements}

This work was financially supported by National Natural Science Foundation of China(No. 51376083) and College Graduate Research and Innovation Projects in Jiangsu Province Year 2013(No. CXZZ13_0672).

\section{References}

[1] U.S.Energy Information Administration. World shale gas resources: An initial assessment of 14 regions outside the United States[M]. 2011,Washington,DC:1-365.

[2] Shale Gas Development Planning(2011-2015)[J].

[3] Gu Xin,Zang Shu-Sheng,et al. Characteristics of Non-Premixed Flame Structure in Humid Air Combustion[J].Journal of Engineering Thermophysics, 2006,27(2):343-346.

[4] Luan Qian-Qian. Numerical Simulation of High Velocity Gas Burner[D].Tianjin University,2007.

[5] Zeng Yi,Fang Jun,Tu Ran,Guan Jin-Fu,Zhang Jun,Zhang Yong-Ming. Variation of Enclosure Fire Ceiling Smoke Concentration with High Altitude[J]. Journal of Combustion Science and Technology, 2011,17(4):332-336.

[6] Zhao Zhen-Xin,Cao Zi-Dong, et al. Study of the Combustion Stability Characteristics of a Direct-flow Type Low-heating-value Coal Gas Burner[J]. Journal of Engineering for Thermal Energy And Power, 2010,25(5):517-520,575-576.

[7] Xiao Xian-Ming,Song Zhi-Guang,Zhu Yan-ming, et al. Summary of shale gas research in North American and revelations to shale gasexploration of Lower Paleozoic strata in China south area[J]. Journal of China Coal Society, 2013,38(5):721-727.

[8] Qiao L, Kim C H, et al.Suppression Effects of Diluents on Laminar Premixed Hydrogen/Oxygen/Nitrogen Flames[J]. Combustion and Flame, 2005, 143(1/2): 79-96. 